\title{
Visual and ocular motor function in the atypical form of neurodegeneration with brain iron accumulation type I
}

\author{
Joana Jesus-Ribeiro, ${ }_{1}^{1}$ Cláudia Farinha, ${ }_{1}^{2,3}$ Margarida Amorim, ${ }^{4}$ Anabela Matos, ${ }^{1,5}$ \\ Aldina Reis, ${ }^{6}$ João Lemos, ${ }^{1}$ Miguel Castelo-Branco, ${ }^{6}$ Cristina Januário ${ }^{1,7}$
}

\begin{abstract}
- Additional material is published online only. To view please visit the journal online (http://dx.doi.org/10.1136/ 10.1136/bjophthalmol-2017310181)
\end{abstract}

'Department of Neurology, Coimbra University Hospital Center, Coimbra, Portugal ${ }^{2}$ Department of Ophthalmology, Coimbra University Hospital Center, Coimbra, Portugal ${ }^{3}$ Association for Innovation and Biomedical Research on Light and Image, Coimbra, Portugal ${ }^{4}$ Department of

Otorhinolaryngology, Coimbra University Hospital Center,

Coimbra, Portugal

${ }^{5}$ Department of

Neurophysiology, Coimbra University Hospital Center, Coimbra, Portugal

${ }^{6}$ Institute for Biomedical Imaging and Life Sciences, Faculty of Medicine, University of Coimbra, Coimbra, Portugal ${ }^{7}$ Faculty of Medicine, University of Coimbra, Coimbra, Portugal

\section{Correspondence to} Dr Joana Jesus-Ribeiro, Coimbra University Hospital Center, Praceta Mota Pinto, Coimbra 3000-075, Portugal; joanajribeiro@gmail.com

Received 10 January 2017 Revised 4 April 2017

Accepted 6 April 2017

\begin{abstract}
Background/aims Neurodegeneration with brain iron accumulation (NBIA) type I is a rare disease that can be divided into a classical or atypical variant, according to age of onset and clinical pattern. Neuroophthalmological involvement has been documented in the classical variant but only anecdotically in the atypical variant. We sought to describe the visual and ocular motor function in patients with atypical form of NBIA type I.

Methods Cross-sectional study, including patients with genetically confirmed NBIA type I and classified as atypical variant, who underwent ophthalmological examination with best corrected visual acuity (BCVA), optical coherence tomography (OCT), fundus autofluorescence (FAF), electroretinography (ERG), visual evoked potentials (VEP) and video-oculography.

Results Seven patients with a mean BCVA of $0.12 \pm 0.14 \log M A R$ were included. Only two patients showed structural evidence of advanced retinopathy in OCT and FAF, and there were no cases of optic atrophy. ERG data, however, showed abnormal scotopic and/or photopic responses in all patients. VEP were normal in all three patients. Ocular fixation was markedly unstable (eg, increased rate of saccadic pulses) in the majority of patients (5). Additional mild ocular motor disturbances included low gain pursuit (2), hypermetric saccades (1), low gain optokinetic (2) and caloric and rotatory responses (3).
\end{abstract}

Conclusion Functional retinal changes associated with marked instability of ocular fixation should be included in the clinical spectrum of NBIA, particularly in the atypical form.

\section{INTRODUCTION}

Neurodegeneration with brain iron accumulation (NBIA) refers to a group of rare heterogeneous neurodegenerative disorders characterised by progressive and severe neurological impairment and excessive iron deposition in the basal ganglia. ${ }^{1-3}$

One of the core syndromes is associated with a recessive mutation in the pantothenate kinase-associated neurodegeneration (PKAN) gene, which accounts for approximately half the cases of NBIA, classified as type I. ${ }^{12}$ NBIA type I can be divided into two major subtypes according to age of onset and clinical progression: the classical variant that occurs early in the first decade of life, with predominant extrapyramidal features and rapid clinical progression; and the atypical variant, which begins in the second or later decades, and extrapyramidal features are generally less severe and more slowly progressive. $^{2-4}$

Neuro-ophthalmological involvement has been described in NBIA type I. ${ }^{125}$ Retinal degeneration seems to be the most consistent finding in classical variant $\left(26 \%,{ }^{6} 68 \%{ }^{2}\right.$ and $20 \%{ }^{4}$ in the three most representative series). Optic neuropathy has been also documented in the classical variant, ${ }^{4} 6$ although Hayflick et $a l^{2}$ considered it to be infrequent (3\%). In 2005, Egan et al ${ }^{5}$ analysed the electroretinographic features in 16 patients with genetically confirmed PKAN, although no clear distinction was made between classical and atypical variants. While a pigmentary retinopathy was documented in only 4 out 10 patients, in around $70 \%$ of patients, there was an abnormal electroretinography (ERG). ${ }^{5}$ In atypical NBIA, visual function has been anecdotally reported, but retinopathy and optic atrophy seem to be rare.

Oculomotor abnormalities in classical NBIA, suggestive of predominant midbrain degeneration, have been reported ${ }^{357}$ including slow vertical saccades, frequent square wave jerks, abnormal vertical optokinetic responses and an inability to suppress the vestibulo-ocular reflex (VOR). ${ }^{5}$ Importantly, detailed ocular motor assessment using video-oculography and video-head impulse test in the atypical form has not been performed to date.

In our study, we provide a detailed visual and ocular motor analysis in patients with the atypical form of NBIA type I.

\section{MATERIALS AND METHODS}

Cross-sectional study including patients with genetically confirmed (ie, mutation in PKAN) NBIA from our Neurogenetics Clinic, with a clinical phenotype consistent with atypical variant. Patients classified as NBIA classic variant, ${ }^{12}$ and those with advanced disease unable to cooperate were excluded.

Informed consent was obtained from all participants, and ethics committee approved the study protocol.

All patients underwent the following clinical assessment:

\section{Visual assessment}

An ophthalmological evaluation was performed including best corrected distance visual acuity (BCVA; Snellen chart), slit lamp examination and dilated fundus exam. 
Additional assessment comprised: (1) colour fundus photography (CFP; Topcon TRC-50EX; Topcon, Tokyo, Japan); mydriatic colour fundus digital photographs were taken centred on the fovea, with a $30^{\circ}$ field of view; (2) spectral domain optical coherence tomography (SD-OCT; Spectralis HRA-OCT, Heidelberg Engineering, Heidelberg, Germany); this was performed using evenly spaced lines scan pattern and the following parameters: $870 \mathrm{~nm}$ acquisition speed, $35000 \mathrm{~A}$-scans per seconds, scan depth: $1.8 \mathrm{~mm}$ and digital depth resolution: approximately $3.5 \mu \mathrm{m}$ per pixel; (3) fundus autofluorescence (FAF) was obtained using a confocal blue laser autofluorescence system $(488 \mathrm{~nm})$ (Heidelberg Engineering, Heidelberg, Germany); after positioning the patient on the camera with the eye aligned for uniform illumination of the retina, the eye was bleached for $30 \mathrm{~s}$ with blue light, and a minimum of 10 frames of images were taken for averaging to get the best possible image; (4) ERG was recorded using RETIscan (Roland Consult, Germany) with DTL-Plus electrodes and with the patients' pupils fully dilated; multifocal ERG was performed according to published methods ${ }^{8}$; full-field ERG was recorded using a Ganzfeld Q450 stimulator according to ISCEV standards ${ }^{9}$; dark-adapted responses were obtained after $20 \mathrm{~min}$ of dark adaption and light-adapted responses after $10 \mathrm{~min}$ of light exposure $\left(30 \mathrm{~cd} . \mathrm{s} / \mathrm{m}^{2}\right)$ in the dome; (5) visual evoked potentials (VEP) were carried out using Nicolet Viking Select software according to the current guidelines for pattern reversal VEP from the American Clinical Neurophysiology Society ${ }^{10}$; full-field stimulation was performed monocularly, using a high-contrast (>50\%) black-and-white checkerboard pattern, at a reversal rate of $4 / \mathrm{s}$.

\section{Ocular motor assessment}

All patients performed binocular video-oculography (VOG; VO425 Firewire Interacoustics; $105 \mathrm{~Hz}$ ). After 5-point calibration, VOG assessment included ocular fixation $(30 \mathrm{~s})$ in dark and light, $20^{\circ}$ gaze testing, $20^{\circ}$ sinusoidal pursuit $(10 \%$, starting velocity), $10-30^{\circ}$ saccades and $20 \%$ optokinetic nystagmus $(\mathrm{OKN})$ both in the horizontal and vertical planes, right, left and head straight supine and head hanging positional testing in dark, and head-shaking-induced nystagmus test (HST) and mastoid vibration-induced nystagmus test (MVT). For smooth pursuit, the mean gain was calculated comparing target and eyes velocities. ${ }^{11}$ By definition a primary saccade was the first saccade within $100-500 \mathrm{~ms}$ after a target step. The time delay between target step and the start of primary saccades was taken as latency. ${ }^{11} 12$ Mean velocity was calculated for each primary saccade. ${ }^{11} 12$ Saccade amplitude was calculated, and the ratio between step and saccade amplitude was taken as the saccade accuracy. ${ }^{11}$ OKN gain was calculated by comparing eye mean velocity and stimulus (stripes or rotation) velocity. HST and MVT were considered positive when stimulation produced a reproducible, sustained nystagmus, with a slow-phase velocity (SPV) higher than $2^{\circ}$ per second. VOR function was further assessed using monocular video-horizontal head impulse test (VHIT; EyeSeeCam Interacoustics; 220 Hz) and caloric and rotatory chair tests (Type Med 4 Synapsis). VHIT was performed with the patient in a seated position in room light. After a successful 5-point calibration, the patient kept fixating a target at $\sim 1.5 \mathrm{~m}$, while about 20 unpredictable head impulses to each side (right and left) were applied by the experimenter. VOR gain was calculated as the ratio of eye to head velocity at $60 \mathrm{~ms}^{13}$ Caloric tests were performed by irrigating the ears for $25 \mathrm{~s}$ alternately with $50 \mathrm{~mL}$ of cold $\left(30^{\circ} \mathrm{C}\right)$ and hot $\left(44^{\circ} \mathrm{C}\right)$ water with a $5 \mathrm{~min}$ interval between ears. The induced nystagmus was recorded monocularly with VOG until it had completely decayed. Asymmetry of vestibular function was calculated using the Jongkees' formula, and caloric paresis was defined by the response difference of $\geq 25 \%$ between the ears. For rotatory chair testing, the patients were seated in a chair in total darkness, while sinusoidal cycles at specific frequencies $(0.16 \mathrm{~Hz}$, $0.32 \mathrm{~Hz}$ and $0.64 \mathrm{~Hz}$ ) were performed.

\section{RESULTS}

Seven patients with disease onset between 14 and 23 years old were included. Four patients were female. The median age was 37 years and median disease duration was 16 years. Patients were genetically heterogeneous, with PKAN mutation 1070 $\mathrm{G}>\mathrm{C}$ transition being the most prevalent $(n=5)$. Demographic and clinical data are presented in table 1.

\begin{tabular}{|c|c|c|c|c|c|c|}
\hline $\begin{array}{l}\text { Patient } \\
\text { number }\end{array}$ & Gender & Age (years) & $\begin{array}{l}\text { Age at disease onset } \\
\text { (years) }\end{array}$ & $\begin{array}{l}\text { Disease duration } \\
\text { (years) }\end{array}$ & Type of mutation & Neurological findings \\
\hline 1 & $\mathrm{~F}$ & 23 & 14 & 9 & $\begin{array}{l}\text { c.1070G >C(p.Arg357Pro) } \\
\text { c.1561G>A(p.Gly521Arg) }\end{array}$ & $\begin{array}{l}\text { Oromandibular dystonia, postural } \\
\text { instability and gait abnormalities. }\end{array}$ \\
\hline 2 & $\mathrm{~F}$ & 37 & 20 & 17 & c.1070G >C(p.Arg357Pro) & $\begin{array}{l}\text { Oromandibular dystonia, } \\
\text { parkinsonism and cognitive } \\
\text { decline. }\end{array}$ \\
\hline 3 & M & 19 & 16 & 3 & c.1070G >C(p.Arg357Pro) & $\begin{array}{l}\text { Arm dystonia, postural } \\
\text { instability and gait abnormalities. }\end{array}$ \\
\hline 4 & $\mathrm{~F}$ & 48 & 23 & 25 & c.1070G >C(p.Arg357Pro) & $\begin{array}{l}\text { Cognitive decline, speech } \\
\text { abnormalities (palilalia) and } \\
\text { parkinsonism. }\end{array}$ \\
\hline 5 & $M$ & 49 & 22 & 27 & $\begin{array}{l}\text { c.1070G }>C \text { (p.Arg357Pro) } \\
\text { c.1211A }>\text { (p.Asn404lle) }\end{array}$ & $\begin{array}{l}\text { Neuropsychiatric manifestations, } \\
\text { oromandibular dystonia and gait } \\
\text { abnormalities. }\end{array}$ \\
\hline 6 & $M$ & 38 & 22 & 16 & c.1583C>T(p.Thr528Met) & $\begin{array}{l}\text { Marked blepharospasm, cognitive } \\
\text { decline and gait abnormalities. }\end{array}$ \\
\hline 7 & $\mathrm{~F}$ & 36 & 20 & 16 & c.1583C>T(p.Thr528Met) & $\begin{array}{l}\text { Marked blepharospasm, } \\
\text { oromandibular dystonia and } \\
\text { cognitive decline. }\end{array}$ \\
\hline
\end{tabular}



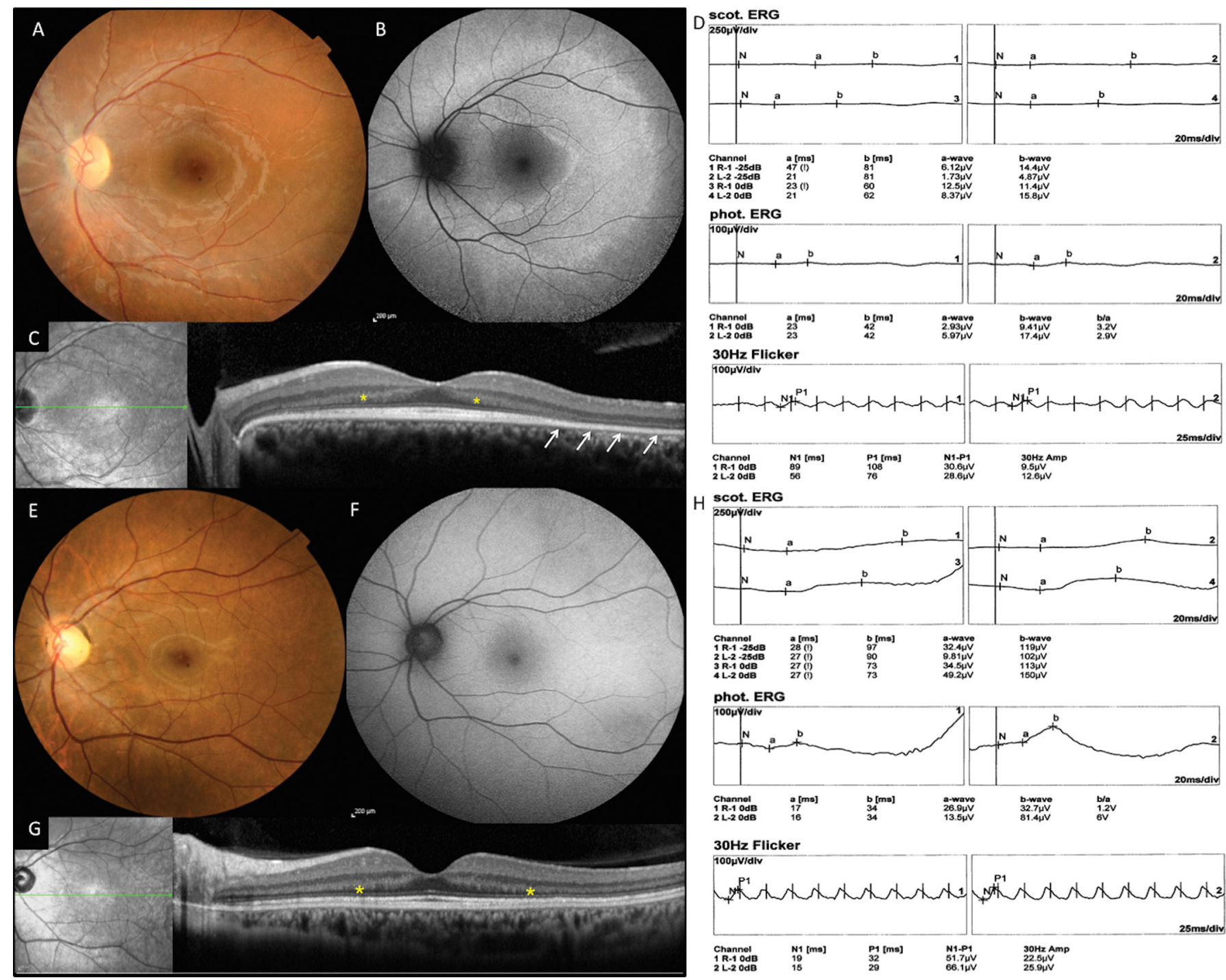

Figure 1 Patient 1 with 20/20 vision in the LE. (A) CFP shows mottling of the RPE, but no pigmentary changes suggestive of pigmentary retinopathy. (B) FAF shows a well demarcated hyperautofluorescent ring surrounding the fovea and the optic disc, with abnormal hypoautofluorescence in the periphery. (C) SD-OCT demonstrates thinning of the outer nuclear layer (yellow asterisks), and disruption and disappearance of the more external retinal layers (white arrows) outside the central macula. Patient 2 with 20/20 vision in LE. (E) CFP shows only discrete mottling of the RPE. (F) FAF is normal. (G) SD-OCT demonstrates thinning of the outer nuclear layer (yellow asterisks), with preservation of the external retinal layers. ERG of patients 1 (D) and 2 (H), showing severe compromise of the rod and cone function. CFP, colour fundus photography; ERG, electroretinography; FAF, fundus autofluorescence; LE, left eye; RPE, retinal pigment epithelium; SD-OCT, spectral domain optical coherence tomography.

\section{Visual findings}

The mean BCVA was 0.12 $\pm 0.14 \log$ MAR, which corresponds to an approximate Snellen visual acuity of 20/25 ( $n=14$ eyes). In all patients, the media were transparent, and fundus and CFP appearance was normal apart from evidencing mild retinal pigment epithelium mottling outside the posterior pole in four patients. There were no subjects demonstrating optic disc pallor, pigment retinal changes or vascular attenuation. In spite of a normal-appearing fundus, two patients (patients 1 and 3) presented with severe bilateral signs of retinopathy in structural exams. Specifically, SD-OCT showed disruption and disappearance of the ellipsoid zone and external limiting membrane, and thinning of the outer nuclear layer (ONL) outside the central macula, with foveal architecture preserved in both cases. Additionally, FAF revealed a corresponding parafoveal ring of hyperautofluorescence, representing retinal metabolic dysfunction surrounding a normal hypoautofluorescent foveal area (figure 1). Importantly, visual acuity in these patients was 20/32 and 20/20. In another three patients (patients 2, 4 and 5), SD-OCT revealed mild thinning of the ONL in both eyes, showing no changes in the external layers. In these subjects, FAF appearance was normal (figure 1). Patient 6 had normal OCT and FAF examination, and for patient 7 , OCT and FAF could not be performed due to poor cooperation.

The scotopic responses were abolished or residual in four patients (patients 1, 3, 4 and 6), while photopic responses were reduced or residual in all except patient 7 . The flicker response was reduced and delayed in the majority of the patients, except for patients 6 and 7. Multifocal ERG revealed mainly focal responses with globally altered morphology but preservation of the central response in the entire group. Relevant ERG findings in our sample are shown in figure 1. VEP could not be performed 


\begin{tabular}{|c|c|c|c|c|c|c|c|}
\hline \multirow{2}{*}{$\begin{array}{l}\text { Patient } \\
\text { number }\end{array}$} & \multicolumn{2}{|l|}{ BCVA } & \multirow{2}{*}{$\begin{array}{l}\text { Fundus } \\
\text { examination* }\end{array}$} & \multirow[b]{2}{*}{ SD-OCT } & \multirow[b]{2}{*}{ FAF } & \multirow[b]{2}{*}{ ERG/ mfERG } & \multirow[b]{2}{*}{ VEP } \\
\hline & RE & LE & & & & & \\
\hline 1 & $20 / 25$ & $20 / 20$ & $\begin{array}{l}\text { Discrete RPE } \\
\text { mottling }\end{array}$ & $\begin{array}{l}\text {-Loss of the ELM and } \\
\text { photoreceptors' IS and OS } \\
\text {-Profound ONL thinning } \\
\text { outside the fovea }\end{array}$ & $\begin{array}{l}\text { Parafoveal } \\
\text { hyperautofluorescent } \\
\text { ring }\end{array}$ & $\begin{array}{l}\text { ERG full-field: Abolished SR, CR and OP. Residual PR. } \\
\text { 'Flicker' reduced and delayed. } \\
\text { mfERG: Globally altered morphology. Preservation } \\
\text { of central response (ring 1) on both eyes, for both } \\
\text { morphology and amplitude. }\end{array}$ & - \\
\hline 2 & $20 / 20$ & $20 / 20$ & $\begin{array}{l}\text { Discrete RPE } \\
\text { mottling }\end{array}$ & Mild thinning of the ONL & Normal & $\begin{array}{l}\text { ERG full-field: Normal SR. Reduced CR, PR and 'flicker' } \\
\text { (asymmetry with lower amplitude in the RE). Residual OP. } \\
\text { mfERG: Some responses with altered morphology. Central } \\
\text { response preserved bilaterally }\end{array}$ & Normal \\
\hline 3 & $20 / 20$ & $20 / 20$ & $\begin{array}{l}\text { Discrete RPE } \\
\text { mottling }\end{array}$ & $\begin{array}{l}\text { Loss of the ELM and } \\
\text { photoreceptors' IS and OS } \\
\text {-Profound ONL thinning } \\
\text { outside the fovea }\end{array}$ & $\begin{array}{l}\text { Parafoveal } \\
\text { hyperautofluorescent } \\
\text { ring }\end{array}$ & $\begin{array}{l}\text { ERG full-field: Abolished SR and CR on LE and residual } \\
\text { on RE. Abolished OP. Reduced PR. Reduced and delayed } \\
\text { 'flicker' response. } \\
\text { mfERG: Focal responses with globally altered morphology. } \\
\text { Preservation of central response (ring 1), with better } \\
\text { range in LE. }\end{array}$ & Normal \\
\hline 4 & $20 / 10$ & $20 / 25$ & Normal & Mild thinning of the ONL & Normal & $\begin{array}{l}\text { ERG full-field: Abolished SR and OP. Residual PR and CR } \\
\text { (mainly LE). 'Flicker' response reduced and delayed. } \\
\text { mfERG: Focal responses with globally altered morphology. } \\
\text { Preservation of central response (ring 1), particularly in } \\
\text { the LE. }\end{array}$ & - \\
\hline 5 & $20 / 50$ & $20 / 40$ & Normal & Mild thinning of the ONL & Normal & $\begin{array}{l}\text { ERG full-field: Normal SR, CR and OP. PR and 'flicker' with } \\
\text { amplitudes below the lower threshold of normality. } \\
\text { mfERG: Some locations within the central } 30^{\circ} \text { core with } \\
\text { reduced amplitude and morphology changes (especially } \\
\text { in the pericentral rings } 2 \text { and } 3 \text { ) in both eyes. Central } \\
\text { response preserved, although asymmetric (lesser extent } \\
\text { in RE). }\end{array}$ & Normal \\
\hline 6 & $20 / 40$ & $20 / 25$ & $\begin{array}{l}\text { Discrete RPE } \\
\text { mottling }\end{array}$ & Normal & $\begin{array}{l}\text { Ring-shaped increased } \\
\text { autofluorescence in the } \\
\text { hypoautofluorescent } \\
\text { central macula. }\end{array}$ & $\begin{array}{l}\text { ERG full-field: Abolished SR. CR with normal amplitudes } \\
\text { but with delayed in RE. Residual potentials on LE and } \\
\text { abolished on RE. PR severely reduced. Normal 'flicker' } \\
\text { response. } \\
\text { mfERG: Focal responses with globally altered morphology, } \\
\text { and preservation of central response (ring 1), particularly } \\
\text { in the LE. }\end{array}$ & - \\
\hline 7 & $20 / 25$ & $20 / 25$ & Normal & - & - & $\begin{array}{l}\text { ERG full-field: Responses within normal limits. } \\
\text { mfERG: Pericentral responses (rings } 2 \text { and 3) showing } \\
\text { focal alterations, particularly in response amplitude. } \\
\text { Central response preserved. }\end{array}$ & - \\
\hline
\end{tabular}

*Fundus examination included colour fundus photography.

-, not performed; BCVA, best corrected visual acuity; CR, combined response; ELM, external limiting membrane; ERG, electroretinography; FAF, fundus autofluorescence; IS, inner segments; LE, left eye; mfERG, multifocal ERG; ONL, outer nuclear layer; OP, oscillatory potentials; OS, outer segments; PR, photopic response; $R E$, right eye; RPE, retinal pigment epithelium; SD-OCT, spectral domain optical coherence tomography; SR, scotopic response; VEP, visual evoked potentials.

in the majority of patients due to involuntary lid and head movements. In patients 2, 3 and 5, P100 wave latency and amplitude was normal.

Patients' visual assessment results are listed in table 2.

\section{Ocular motor findings}

Detailed ocular motor analysis was available in seven patients. Frequent saccadic intrusions interrupting ocular fixation were frequent in our sample and included pervasive single saccadic pulses in three patients (patients 1,3 and 6) and continuous square wave jerks (SWJ) in three patients (patients 1, 2 and 5) (figure 2 and video - supplementary data). Patient 4 showed left beating nystagmus (SPV: $2.2 \% \mathrm{seg}$ ) only in dark. Mean smooth pursuit gain was uniformly low $(<0.8)$ in only two patients (patients 6 and 7). Saccade velocity (vertical and horizontal) was normal in the entire sample, ranging between 333 and $633 \%$ s. Saccades overshooting the target (hypermetric) were observed in patient 3 . OKN responses were slightly reduced in two patients (patients 2 and 6). Positional nystagmus in dark was detected in two patients (patients 4 and 6). HST was normal in all patients tested. MVT, however, induced horizontal nystagmus in four patients (patients 1, 2, 4 and 6). Positional testing, HST and MVT were not performed in patient 7 due to severe motor restriction. VOR evaluation showed essentially normal VHIT responses (range 0.83-1.20), mild hyporesponsiveness under rotatory stimulation in two patients (patients 3 and 6) and caloric hyporesponsiveness in two patients (patient 5 and 6).

Ocular motor data are listed in table 3.

\section{DISCUSSION}

Our results showed that in spite of a normal visual acuity and almost normal fundus appearance, all patients with atypical NBIA evidenced some degree of retinal dysfunction, with two patients additionally showing a clear structural retinopathy. Importantly, marked fixation instability (ie, saccadic pulses and square wave jerks) was detected in the majority of patients.

All our patients showed abnormal ERG responses, indicating both cone and rod widespread dysfunction. Of these, only two patients showed clear morphological changes in OCT and FAF, suggesting more advanced cone-rod retinal degeneration. 


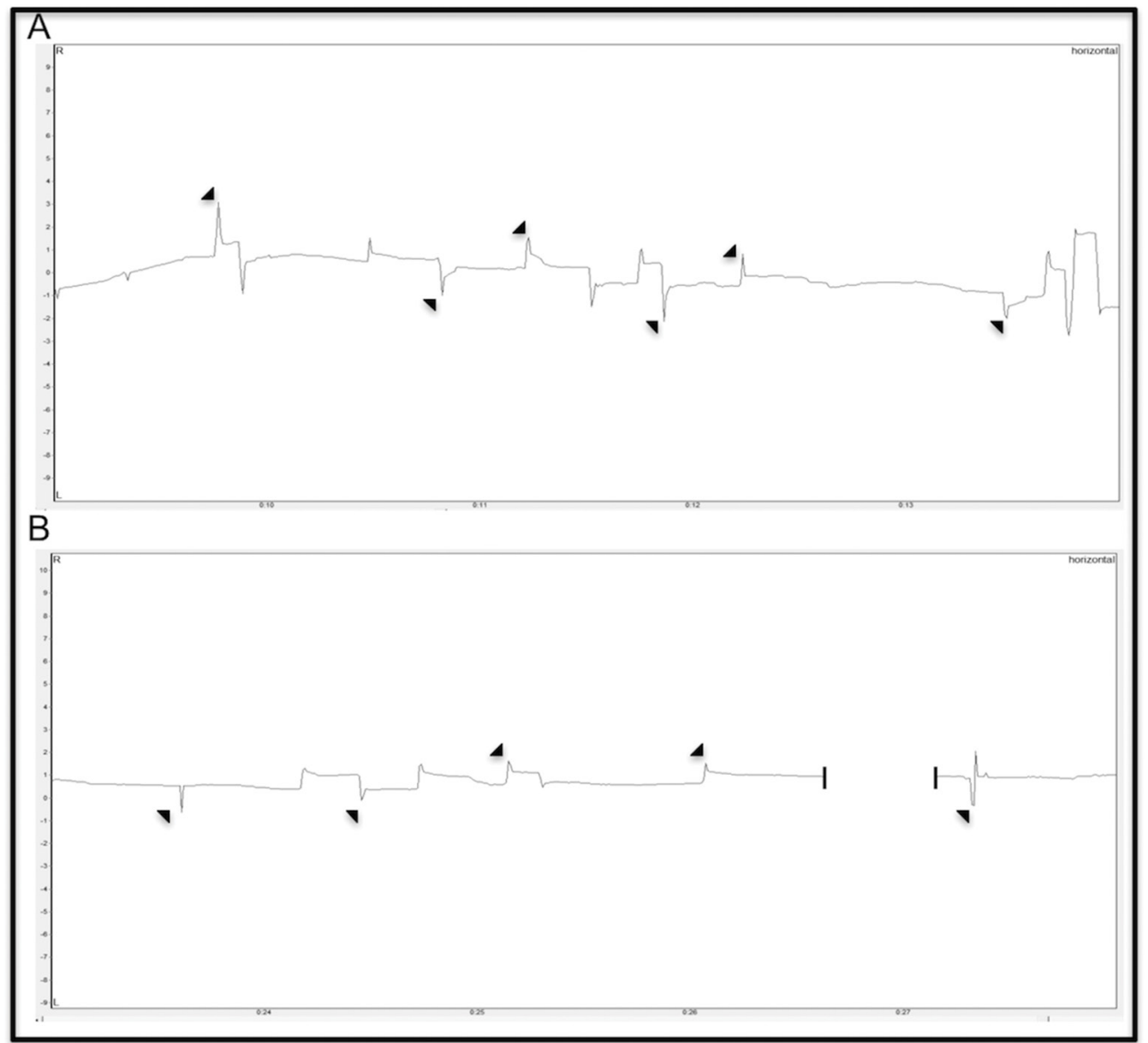

Figure 2 (A) Patient 1 presenting SP (arrow) $\left(2.4 / \mathrm{seg}_{;}<3^{\circ}\right)$, sometimes followed by SWJ $\left(55 / \mathrm{min} ;<5^{\circ}\right)$. (B) Patient 3 demonstrating frequent SP (arrow) $\left(1.2 / \mathrm{seg}<2^{\circ}\right)$. SP, saccadic pulses; SWJ, square wave jerks.

Strikingly, fundus exam and CFP were normal in all patients. These results are in line with previous histopathological studies in two patients with classic variant, reporting loss of the photoreceptor cells and the degeneration of outer nuclear and outer plexiform layers. ${ }^{7}{ }^{14}$ Egan and colleagues studied electroretinographic responses in patients with NBIA without clearly differentiating between classical and atypical variants. ${ }^{5}$ In their series, the majority of patients presented ERG abnormalities, ranging from mild to severe rod-cone dysfunction. ${ }^{5}$ Retinal dysfunction in NBIA has been ascribed to iron overload and coenzyme A deficit . ${ }^{1415}$ Iron is particularly important for the visual phototransduction cascade and in hereditary iron homeostasis disorders such as NBIA, retinal iron buildup leads to the production of toxic reactive oxygen species, thus contributing to retinal degeneration. ${ }^{15}$ Additionally, PKAN is an essential regulatory enzyme in the production of coenzyme A. ${ }^{1}$ PKAN mutations may lead to coenzyme A depletion, which in tissues with high coenzyme A consumption such as retina, may also contribute to the development of retinopathy in these patients. ${ }^{14} 15$ Overall, our data on visual function in patients with atypical NBIA indicate that retinal degeneration occurs both in classical and atypical variants of NBIA and not only in the former type as initially thought. Moreover, the use of more sensitive diagnostic testing (eg, ERG) is required in these patients for detecting retinal dysfunction at an earlier phase. There were no patients showing imaging and/ or structural evidence of optic atrophy, and three additional patients also demonstrated normal VEP. These data in atypical
NBIA support the sparing of the optic nerve, ${ }^{5}$ in contrast with previous reports of optic atrophy in classical variant, probably secondary to retinal degeneration. ${ }^{12}$

Ocular motor data indicate that the atypical variant NBIA is associated with marked instability of ocular fixation. Frequent SWJ, but also pervasive SP, were found in the majority of patients. The underlying mechanism for pathological SWJ (ie, frequent, large and multidirectional) is still unclear, but their presence may reflect a dysfunctional inhibitory system (including basal ganglia and cerebellum), which is no longer suppressing unwanted saccades during ocular fixation. ${ }^{16}{ }^{17}$ However, pervasive SP have been less frequently described in the literature and, to our knowledge, never before in patients with NBIA. ${ }^{16}$ The mechanism underlying the generation of SP seems to be similar to that of SWJ. ${ }^{16}{ }^{17}$ Future studies in a larger number of patients should explore their diagnostic potential in NBIA. Ocular pursuit was mildly impaired in a subset of patients, supporting the existence of widespread cortical/subcortical (and possibly brainstem and/ or cerebellar) dysfunction in NBIA. ${ }^{18} 19$ Apart from the presence of hypermetric saccades suggesting cerebellar dysfunction in one patient, ${ }^{12}$ saccades in our sample were generally spared. This contrasts with Egan et al's ${ }^{35}$ findings in a younger NBIA group. Here the authors demonstrated that slow vertical saccades were frequently present, suggesting midbrain degeneration, although a differentiation between classical and atypical variants was not established. Therefore, brainstem saccade-generating centres may be spared in the atypical variant of NBIA. Both vertical and horizontal OKN responses were mildly impaired in two patients. 
Table 3 Ocular motor findings

\begin{tabular}{|c|c|c|c|c|c|c|c|c|c|}
\hline $\begin{array}{l}\text { Patient } \\
\text { number }\end{array}$ & Fixation & $\begin{array}{l}\text { Smooth } \\
\text { pursuit } \\
\text { (gain) }\end{array}$ & $\begin{array}{l}\text { Saccades } \\
\text { (latency; average } \\
\text { velocity; gain) }\end{array}$ & $\begin{array}{l}\text { OKN } \\
\text { (gain) }\end{array}$ & MVT & HST & $\begin{array}{l}\text { VHIT } \\
\text { (gain) }\end{array}$ & Rotatory chair tests & Caloric tests \\
\hline 1 & $\begin{array}{l}\text { Frequent SP* }(2.4 / \\
\left.\text { sec; }<3^{\circ}\right) \\
\text { Frequent SWJ }(0.9 / \\
\left.\text { sec } ;<5^{\circ}\right)\end{array}$ & $\begin{array}{l}H: 0.8 \\
V: 0.8\end{array}$ & $\begin{array}{l}\mathrm{H}: 160 \mathrm{~ms} ; 482^{\circ} \\
\mathrm{sec} ; 0.8 \\
\text { V: } 164 \mathrm{~ms} ; 633^{\circ} \% \\
\mathrm{sec} ; 1.0\end{array}$ & $\begin{array}{l}H: 94 \% \\
\text { V: } 90 \%\end{array}$ & $\begin{array}{l}\text { LBN (SPV } 4.8^{\circ} / \\
\text { sec) }\end{array}$ & Normal & $\begin{array}{l}\text { R: } 1.20 \\
\text { L: } 0.90\end{array}$ & Symmetric responses & LUW: 7\% \\
\hline 2 & 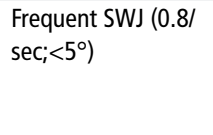 & $\begin{array}{l}H: 0.8 \\
V: 0.8\end{array}$ & $\begin{array}{l}\mathrm{H}: 199 \mathrm{~ms} ; 374 \% \\
\mathrm{sec} ; 0.8 \\
\text { V: } 221 \mathrm{~ms} ; 333^{\circ} / \\
\text { sec; } 0.9\end{array}$ & $\begin{array}{l}H: 77 \% \\
V: 57 \%\end{array}$ & $\begin{array}{l}\text { RBN } \\
\text { (SPV } 4.5 \% / s e c)\end{array}$ & Normal & $\begin{array}{l}\text { R: } 1.10 \\
\text { L: } 1.17\end{array}$ & Symmetric responses & LUW: 19\% \\
\hline 3 & $\begin{array}{l}\text { Frequent } S P^{*}(1.21 \\
\left.\mathrm{sec} ;<2^{\circ}\right)\end{array}$ & $\begin{array}{l}H: 0.8 \\
V: 0.8\end{array}$ & $\begin{array}{l}\mathrm{H}: 205 \mathrm{~ms} ; 560^{\circ} \\
\mathrm{sec} ; 1.1 \\
\text { V: } 156 \mathrm{~ms} ; 541 \% \\
\mathrm{sec} ; 1.1\end{array}$ & $\begin{array}{l}\text { H: } 108 \% \\
\text { V: } 104 \%\end{array}$ & No nystagmus & Normal & $\begin{array}{l}\text { R: } 1.00 \\
\text { L: } 1.10\end{array}$ & $\begin{array}{l}\text { Symmetric responses at } 0.32 \\
\text { and } 0.64 \mathrm{~Hz} \text {. Hyporeflexive } \\
\text { responses at } 0.16 \mathrm{~Hz} \text {. }\end{array}$ & LUW: $13 \%$ \\
\hline 4 & LBN (SPV: $\left.2.2^{\circ} / \mathrm{sec}\right)$ & $\begin{array}{l}H: 0.7 \\
V: 0.9\end{array}$ & - & - & $\begin{array}{l}\text { RBN } \\
\text { (SPV 8.5\%/sec) }\end{array}$ & Normal & $\begin{array}{l}\mathrm{R}: 0.93 \\
\mathrm{~L}: 0.90\end{array}$ & - & - \\
\hline 5 & $\begin{array}{l}\text { Frequent SWJ }(1.5 / \\
\left.\mathrm{sec}_{,}<5^{\circ}\right)\end{array}$ & $\begin{array}{l}H: 0.8 \\
\text { V: } 0.8\end{array}$ & $\begin{array}{l}\text { H: } 237 \mathrm{~ms}: 444^{\circ} \\
\text { sec; } 0.9 \\
\text { V: } 266 \mathrm{~ms} ; 388 \% \\
\text { sec; } 0.8\end{array}$ & $\begin{array}{l}H: 94 \% \\
V: 93 \%\end{array}$ & No nystagmus & Normal & $\begin{array}{l}\text { R: } 1.05 \\
\text { L: } 0.99\end{array}$ & - & RUW: $85 \%$ \\
\hline 6 & 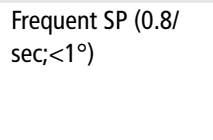 & $\begin{array}{l}\mathrm{H}: 0.7 \\
\mathrm{~V}: 0.7\end{array}$ & $\begin{array}{l}\mathrm{H}: 250 \mathrm{~ms} ; 472 \% \\
\mathrm{sec} ; 0.8 \\
\text { V: } 286 \mathrm{~ms} ; 529 \% \\
\mathrm{sec} ; 0.8\end{array}$ & $\begin{array}{l}H: 67 \% \\
\text { V: } 69 \%\end{array}$ & $\begin{array}{l}\text { RBN } \\
\text { (SPV } 3.0 \% / \mathrm{sec})\end{array}$ & Normal & $\begin{array}{l}\text { R: } 0.96 \\
\text { L: } 0.83\end{array}$ & $\begin{array}{l}\text { Hyporeflexive responses at } \\
0.16 \text { and } 0.32 \mathrm{~Hz} \text {. }\end{array}$ & LUW: 34\% \\
\hline $7^{\dagger}$ & Normal & $\begin{array}{l}\mathrm{H}: 0.7 \\
\mathrm{~V}: 0.7\end{array}$ & - & $\begin{array}{l}\text { H: } 101 \% \\
\text { V: } 110 \%\end{array}$ & - & - & $\begin{array}{l}\mathrm{R}: 1.11 \\
\mathrm{~L}: 1.12\end{array}$ & - & - \\
\hline
\end{tabular}

*Both deep brain stimulation on and off.

tIn terms of ocular motor assessment, vertical and horizontal pursuit was slightly decomposed, vertical and horizontal saccade speed and amplitude seemed normal at bedside, as well as horizontal head impulse.

-, not performed; H, horizontal; HST, head-shaking-induced nystagmus test; L, left; LBN, left beating nystagmus; LUW, left unilateral weakness; MVT, mastoid vibration-induced nystagmus test; OKN, optokinetic nystagmus; R, right; RBN, right beating nystagmus; RUW, right unilateral weakness; SP, saccadic pulses; SPV, slow-phase velocity; SWJ, Square wave jerks; V, vertical; VHIT, video-horizontal head impulse test.

Since the OKN system shares similar neural circuitry to the pursuit and vestibular systems, concomitant involvement of the latter circuitries in these patients might justify OKN decreased gain. ${ }^{20}$ Finally, VOR function, especially at low and intermediate frequencies (caloric and rotatory responses), was impaired in three out of seven patients. This is a novel clinical finding in patients with atypical NBIA and deserves further investigation. While to date, there has been no evidence for intrinsic involvement of the vestibular system in NBIA, cerebellar damage may play a role in VOR dysfunction. ${ }^{14}{ }^{14}$ Indeed, cerebellum is known to modulate VOR responses, and a cerebellar lesion may promote changes in the VOR gain. ${ }^{21-23}$ Interestingly, histopathological and functional evidence for cerebellar involvement in NBIA has been provided. ${ }^{2425}$

Our study has limitations. The small number of patients included, clinically and genetically heterogeneous, prevented us from establishing putative genotype-phenotype correlations. Our transversal assessment also precluded any conclusion regarding the progression of the visual damage in atypical NBIA. Nevertheless, we were able to provide a comprehensive analysis of the afferent and efferent visual systems in the atypical form of NBIA.

In sum, similarly to the classical type, only a minority of patients with atypical NBIA showed structural evidence of retinopathy, while they all demonstrated retinal functional changes. Optic nerve and saccade network however seem to be spared in the atypical form of the disease. Importantly, the presence of retinopathy and marked fixation instability, including the presence of pervasive saccadic pulses, in a young adult presenting with dystonia and cognitive decline should raise the suspicion for the atypical form of NBIA.
Contributors J J-R: design of the study, data collection, analysis and interpretation of the data and writing the manuscript. CF: performance of ophthalmological examination, CFP, FAF and OCT, analysis and interpretation of the data and revising the manuscript. M A: performance of otorhinolaryngological examination, rotatory chair tests and caloric tests, interpretation of the data and revising the manuscript. AM: performance of VEP, analysis and interpretation of the data and revising the manuscript. AR: performance of ERG, analysis and interpretation of the data and revising the manuscript. JL: design of the study, performance of VOG and VHIT, analysis and interpretation of the data and revising the manuscript. MC-B: design of the study, performance of ERG, analysis and interpretation of the data and revising the manuscript. CJ: design of the study, analysis and interpretation of the data and revising the manuscript.

Competing interests None declared.

Provenance and peer review Not commissioned; externally peer reviewed.

(c) Article author(s) (or their employer(s) unless otherwise stated in the text of the article) 2017. All rights reserved. No commercial use is permitted unless otherwise expressly granted.

\section{REFERENCES}

1 Kurian MA, Hayflick SJ. Pantothenate kinase-associated neurodegeneration (PKAN) and PLA2G6-associated neurodegeneration (PLAN): review of two major neurodegeneration with brain iron accumulation (NBIA) phenotypes. Int Rev Neurobiol 2013;110:49-71.

2 Hayflick SJ, Westaway SK, Levinson B, et al. Genetic, clinical, and radiographic delineation of Hallervorden-Spatz syndrome. N Engl J Med 2003;348:33-40.

3 Schneider SA, Hardy J, Bhatia KP. Syndromes of neurodegeneration with brain iron accumulation (NBIA): an update on clinical presentations, histological and genetic underpinnings, and treatment considerations. Mov Disord 2012;27:42-53.

4 Thomas M, Hayflick SJ, Jankovic J. Clinical heterogeneity of neurodegeneration with brain iron accumulation (Hallervorden-Spatz syndrome) and pantothenate kinaseassociated neurodegeneration. Mov Disord 2004;19:36-42.

5. Egan RA, Weleber RG, Hogarth P, et al. Neuro-ophthalmologic and electroretinographic findings in pantothenate kinase-associated neurodegeneration 
(formerly Hallervorden-Spatz syndrome). Am J Ophthalmol 2005;140:267-74.

6 Dooling EC, Schoene WC, Richardson EP. Hallervorden-Spatz syndrome. Arch Neurol 1974;30:70-83.

7 Luckenbach MW, Green WR, Miller NR, et al. Ocular clinicopathologic correlation of Hallervorden-Spatz syndrome with acanthocytosis and pigmentary retinopathy. Am J Ophthalmol 1983;95:369-82.

8 Hood DC, Bach M, Brigell M, et al. ISCEV standard for clinical multifocal electroretinography (mfERG) (2011 edition). Doc Ophthalmol 2012;124:1-13.

9 Marmor MF, Fulton AB, Holder GE, et al. ISCEV Standard for full-field clinical electroretinography (2008 update). Doc Ophthalmol 2009;118:69-77.

10 Recommended Standards for Visual Evoked Potentials. American Clinical Neurophysiology Society 2008.

11 Mariotti C, Alpini D, Fancellu R, et al. Spinocerebellar ataxia type 17 (SCA17): oculomotor phenotype and clinical characterization of 15 italian patients. J Neurol 2007:254:1538-46

12 Wessel K, Moschner C, Wandinger KP, et al. Oculomotor testing in the differential diagnosis of degenerative ataxic disorders. Arch Neurol 1998;55:949.

13 MacDougall HG, Weber KP, McGarvie LA, et al. The video head impulse test: diagnostic accuracy in peripheral vestibulopathy. Neurology 2009;73:1134-.

14 Tripathi RC, Tripathi BJ, Bauserman SC, et al. Clinicopathologic correlation and pathogenesis of ocular and central nervous system manifestations in HallervordenSpatz syndrome. Acta Neuropathol 1992;83:113-9.

15 He X, Hahn P, lacovelli J, et al. Iron homeostasis and toxicity in retinal degeneration. Prog Retin Eye Res 2007;26:649-73.
16. Lemos J, Eggenberger E. Saccadic intrusions: review and update. Curr Opin Neurol 2013;26:59-66.

17 Zee DS, Robinson DA. A hypothetical explanation of saccadic oscillations. Ann Neurol 1979:5:405-14.

18. Pierrot-Deseilligny C, Gaymard B. Smooth pursuit disorders. Baillieres Clin Neurol 1992;1:435-54

19. Pierrot-Deseilligny C. Saccade and smooth-pursuit impairment after cerebral hemispheric lesions. Eur Neurol 1994;34:121-34.

20 Knapp CM, Proudlock FA, Gottlob I. OKN asymmetry in human subjects: a literature review. Strabismus 2013;21:37-49.

21 Zee DS, Yamazaki A, Butler PH, et al. Effects of ablation of flocculus and paraflocculus of eye movements in primate. J Neurophysio/ 1981;46:878-99.

22 Waespe W, Cohen B, Raphan T. Role of the flocculus and paraflocculus in optokinetic nystagmus and visual-vestibular interactions: effects of lesions. Exp Brain Res 1983;50:9-33.

23 Cohen H, Cohen B, Raphan T, et al. Habituation and adaptation of the vestibuloocular reflex: a model of differential control by the vestibulocerebellum. Exp Brain Res 1992;90:526-38.

24 Neumann M, Adler S, Schlüter 0 , et al. Alpha-synuclein accumulation in a case of neurodegeneration with brain iron accumulation type 1 (NBIA-1, formerly Hallervorden-Spatz syndrome) with widespread cortical and brainstem-type lewy bodies. Acta Neuropathol 2000;100:568-74.

25 Szyszko TA, Dunn JT, O'Doherty MJ, et al. Role of (1)(8)F-FDG PET imaging in paediatric primary dystonia and dystonia arising from neurodegeneration with brain iron accumulation. Nucl Med Commun 2015;36:1-76. 


\section{Visual and ocular motor function in the atypical form of neurodegeneration with brain iron accumulation type I}

Joana Jesus-Ribeiro, Cláudia Farinha, Margarida Amorim, Anabela Matos, Aldina Reis, João Lemos, Miguel Castelo-Branco and Cristina Januário

Br J Ophthalmol published online May 9, 2017

Updated information and services can be found at:

http://bjo.bmj.com/content/early/2017/05/09/bjophthalmol-2017-31018 1

These include:

References This article cites 24 articles, 1 of which you can access for free at: http://bjo.bmj.com/content/early/2017/05/09/bjophthalmol-2017-31018 1\#BIBL

Email alerting

Receive free email alerts when new articles cite this article. Sign up in the service box at the top right corner of the online article.

\section{Notes}

To request permissions go to:

http://group.bmj.com/group/rights-licensing/permissions

To order reprints go to:

http://journals.bmj.com/cgi/reprintform

To subscribe to BMJ go to:

http://group.bmj.com/subscribe/ 